\title{
REESCRITURAS DEL GÉNERO POLICÍACO EN LA FICCIÓN SERIAL: LA MUERTE, LA BRÚJULA Y EL MONSTRUO EN BREAKING BAD ${ }^{1}$
}

\author{
REWRITTINGS OF DETECTIVE GENRE IN SERIAL FICTION: \\ DEATH, THE COMPASS AND THE MONSTER IN BREAKING BAD
}

\author{
Xaquín NÚÑEZ SABARÍS \\ Universidade do Minho \\ xnunez@ilch.uminho.pt
}

\begin{abstract}
Resumen: La serie Breaking Bad, idea original de Vince Gilligan, representa el auge y legitimación cultural (y académica) de la ficción televisiva en los últimos años. La nueva oferta de series, amparada en un nuevo modelo de negocio televisivo y digital, ha conllevado una renovación de los hábitos culturales, transcendiendo su consideración de géneros audiovisuales menores y estimulando una importante democratización estética. Al incorporar talento creativo en los guiones e interpretación, así como una sobresaliente producción, las series se han situado en la zona noble de la cultura audiovisual y la narración artística contemporánea, incorporando mecanismos propios de otros soportes mediales, como la literatura.

La historia de Walter White, padre de familia y despiadado narco, se construye sobre una trama de intriga y persecuciones, que se resuelve por una nota manuscrita en un ejemplar de Leaves of grass. De Whitman a Borges repasaremos los préstamos culturales e intermediales en la creación de este juego de espejos, identidades vacilantes y tramas laberínticas.
\end{abstract}

Palabras clave: Borges; Breaking Bad; narrativas intermediales; literatura; televisión

Abstract: The series Breaking Bad, original idea of Vince Gilligan, represents cultural (and academic) boom and legitimacy of TV fiction in recent years. The new series offering, covered by a new model of TV and digital business, has led to a renewal of cultural habits, transcending to its

\footnotetext{
${ }^{1}$ Este artículo forma parte de un estudio más amplio sobre la relación intermedial entre la narrativa literaria y las series televisivas y, específicamente, sobre Breaking Bad. Se ha realizado en el marco del Grupo de Investigación «Identidade(s) e Intermedialidade(s) del Centro de Estudos Humanísticos da Universidade do Minho.
} 
360 | Tropelías. Revista de Teoría de la Literatura y Literatura Comparada, 31 (2019) Xaquín Núñez Sabarís

consideration of minor audiovisual genres and stimulating an important aesthetic democratization. By incorporating creative talent in the scripts and interpretation, as well as outstanding production, the series has been placed in the zone of audiovisual culture and contemporary artistic narrative, incorporating mechanisms of other media medium, such as literature.

The story of Walter White, father of a family and ruthless narco, is built on a plot of intrigue and persecution, which is resolved by a handwritten note on a copy of Leaves of grass. From Whitman to Borges, we will review the cultural and intermedial loans in the creation of this game of mirrors, faltering identities and labyrinthine plots.

Key words: Borges; Breaking Bad; intermedial narratives; literature; TV series 


\section{Literatura y ficción serial: transferencias narrativas}

Borges, en su introducción y traducción de Hojas de hierba, de Walt Whitman, define a su autor como «esa criatura de naturaleza biforme [...]. Whitman, insisto, es el modesto hombre que fue desde 1819 hasta 1892 y el que hubiera querido ser y no acabó de ser y también cada uno de nosotros y de quienes poblarán el planeta» (Borges, 1991: 9-10). La caracterización que el bonaerense hace del neoyorquino bien podría aplicarse al protagonista de Breaking Bad. Walter White, en sus últimos años de vida - los que abarca el argumento de la serie-, cumple con esta naturaleza biforme, a través de su máscara maléfica, Heisenberg. Quizás es, en este último instante, en el que consigue realizar la fantasía del hombre que siempre quiso ser, aunque ello lo lleve por una deriva de crimen y devastación. Esta huida hacia el mal no resulta, sin embargo, una transformación unidireccional. A lo largo de la serie el protagonista vive y se debate entre un difícil equilibrio entre White y Heisenberg ${ }^{2}$.

Muy probablemente, Vince Gilligan, a medida que creaba y escribía los capítulos del drama, fue consciente de esta criatura frankensteineana que incorporaba la escritura poliédrica de Whitman. Por eso, en un inequívoco guiño a la referencialidad intermedial de la literatura en la narrativa audiovisual, le otorga al poemario Leaves of grass un destacado lugar en el desarrollo de la trama y pone en relación el ingenio químico de White con el literario de Whitman, cuyas iniciales compartidas, WW, generan un conceptual equívoco en el relato.

Los vasos comunicantes de Whitman nos llevan, pues, a Borges y a su metafísico relato policíaco, cuyos mecanismos narrativos podemos advertir en la construcción de Breaking Bad. Allí la cábala y aquí la química construirán una intriga y un suspense, que, rompiendo los moldes clásicos del género, apelan a la ambigüedad interpretativa y a la cooperación activa del espectador. Aquel que, como afirma Vila Matas (2013), a propósito de esta serie, traspasa el umbral del entretenimiento para adentrarse en una compleja ficción que apela a la competencia narrativa del consumidor, al espectador que también puede comprender las referencias literarias de Whitman y Borges. La reflexión del escritor catalán, a propósito de la serie, pone, pues, el acento en el poder transformador de la química y en la «contaminación», en la que observa el código cifrado de este drama televisivo.

De modo que en este trabajo, y siguiendo la orientación intermedial de los estudios de literatura comparada y su eficacia para la descripción de las prácticas culturales contemporáneas ${ }^{3}$, pretendemos advertir las transferencias narrativas y discursivas en la construcción de este monstruo posmoderno y en la reescritura del género policíaco en Breaking Bad, como antes Borges lo había hecho en «La muerte y la brújula».

\footnotetext{
${ }^{2}$ El prólogo de Borges y la relación entre la dualidad de Whitman y la construcción de Walter White ya fue advertida por Hernández Santaolalla (2013: 140): «La obra de Whitman se ha convertido en una de las piezas claves de la serie, y Hoja de hierba da buena cuenta de ello. En éste, el autor da vida a un héroe con dos identidades interrelacionadas, una «criatura [...] de naturaleza biforme», que es a la vez él mismo y aquel que quería ser, según recoge Borges en su prólogo».

${ }^{3}$ Véase, sobre el concepto de intermedialidad y estudios literarios, Rajewsky (2005), Clüver (2011), Sánchez Mesa y Baetens (2017), Prieto (2017) o Pérez Bowie y Gil González (2017)
} 
Esta ficción televisiva es un excelente ejemplo de la nueva realidad global y cultural. Tras ser descartada por HBO comenzó a emitirse en la cadena estadounidense de pago AMC el 20 de enero de 2008 y concluía la quinta temporada el 29 de septiembre de 2013, venciendo las dudas iniciales de los ejecutivos, sobre la arriesgada narración de Vince Gilligan (2008). A partir de ahí, la historia es bastante conocida: la serie forma parte de un importante grupo de series televisivas que, iniciadas a finales de los 90, en las programaciones del canal de pago HBO, han supuesto una renovación importante de las narrativas fílmicas en soporte televisivo. Breaking Bad, junto a The Sopranos, The wire o Lost ha supuesto un auténtico fenómeno mediático y han recabado la atención de análisis y monográficas sobre la ficción televisada o estudios teóricos sobre la narrativa contemporánea (Sepinwall, 2013, Martin, 2014 o Cobo Durán y Hernández Santaolalla, 2013).

La historia de Walter White, de anodino profesor de química a capo de la droga, dibuja un monstruo insólito, posmoderno, en la medida que la ambigua y compleja arquitectura narrativa nos lleva a cuestionarnos sobre las vacilaciones del hombre contemporáneo, de sus interacciones con la sociedad de su tiempo y con las respuestas éticas y morales que se ofrecen. La narración, que exige el esfuerzo interpretativo del espectador, refleja motivos recurrentes en los textos literarios más clásicos. He aquí una historia para los detectives salvajes de Bolaño.

\section{Género policíaco y literatura}

Quizá la mayor enseñanza de Borges sea la certeza de que la ficción no depende sólo de quien la construye sino también de quien la lee. La ficción es también una posición del intérprete. No todo es ficción (Borges no es Derrida, no es Paul de Man), pero todo puede ser leído como ficción y de creer en su poder. La ficción como una teoría de la literatura (Piglia, 2005: 28).

No deja de ser paradójico que el elemento que desnude el ovillo del misterioso Heisenberg, que tiene en jaque a toda la DEA de Albuquerque, así como a los cárteles de droga del sur de Estados Unidos y el norte de México, sea una nota manuscrita a un libro de Walt Whitman, cuyas iniciales coinciden con nuestro protagonista. No deja de ser paradójico, en una serie de paradojas, que sea la sensibilidad en la poesía de la química lo que termina por condenar al cauteloso y precavido Walter White. ¿Guiño consciente del guion? Lo cierto es que Vince Gilligan, creador y productor de la serie, se afanó en presentar un producto cultural que transcendiese la maniquea historia de buenos y malos y lo dotase de un complejo juego de identidades, persecuciones e interrogantes sobre la interacción individuo-sociedad. Consciente o no, la literatura nos ofrece algunas respuestas para explicar e interpretar las claves constructivas de Breaking Bad.

La serie se conduce sobre una estructura de narración policial, en forma de juego ${ }^{4}$. En efecto, desde la primera temporada, Walter parece gozar con la persecución de Hank al misterioso Heisenberg, diseminando el terreno de pistas que, ahora atraen, ahora repelen las indagaciones de su cuñado. La

\footnotetext{
4 «Sabíamos que había una cierta historia entre Walt y Gustavo y que, de alguna forma, teníamos todos los ingredientes necesarios para crear una gran partida de ajedrez» (Gilligan y Van DerWerf, 2013: 62).
} 
sagacidad de Walter, de hecho, supone una inversión de las convenciones del género policíaco, al ser presentado desde la perspectiva del forajido. Esta investigación policial no se construye sobre vacíos de información: todo se presenta a vista del espectador. La privilegiada mente analítica de White apunta a la naturaleza epistemológica del género, ya abordada por Benjamin, que apreciaba en la novela policíaca y en el detective literario, el ejemplo más acabado de modernidad y de flâneur, de intelecto privilegiado en las confusas y masivas urbes modernas:

Em tempos de terror, quando cada um tem algo de conspirador, todos podem também desempenhar o papel de detective. A flânerie oferece para isso as melhores perspectivas. «O observador», diz Baudelaire, «é um príncipe que em toda parte faz uso pleno do seu estatuto de incógnito». Quando o flâneur se torna, assim, um detetive malgré lui, a transformação convém-lhe socialmente, porque legitima o seu ócio. A sua indolência é apenas aparente. Por detrás dela esconde-se o olhar desperto de um observador que não perde de vista o malfeitor. Assim, o detetive vê abrirem-se à sua autoestima vastos domínios. Desenvolve formas de reação adequadas ao ritmo da grande cidade. Capta as coisas fugidias, e com isso sonha estar próximo do artista (Benjamin, 2015: 43).

La autoestima y narcisismo son aspectos que van a tener mucha incidencia en la configuración de la personalidad de Walter y su transformación en Heisenberg: harto de su invisibilidad social, goza con la creatividad artística en la transformación química y manifiesta una creciente vanidad en su papel de malvado. La narración detectivesca es, por tanto, el género epistemológico por excelencia, apuntalado por McHale (1987: 9) y Piglia (2005), quien observa este trasvase del detective a la cultura de masas:

El detective se interna en el mundo de la cultura de masas y actúa como un experto. Los periódicos son el escenario cotidiano del crimen. Y el género es su doble: nace allí y nace para leer de otro modo y así cortar el flujo de lo que no se deja descifrar. El refinado lector que es Dupin, formado en las librerías de París, en los libros únicos y raros, en la frecuentación de alta cultura, leerá los periódicos como nadie los ha leído antes. Leerá, de un modo microscópico, la tensión que circula en todo el universo social (Piglia, 2005: 84).

Bolaño, por ejemplo, llevará al extremo esta interacción entre literatura y persecución en Los detectives salvajes, apurando el rastro esquivo de los real visceralistas y de Cesárea Tinarejo, que se pierde en el desierto de Sonora, próximo a las vastedades desérticas de Nuevo México en que transcurre parte de la historia de Breaking Bad.

La posmodernidad ofrece, en relación con esta clarividente epistemología, un giro más y ya no se trata de observar cómo percibimos la realidad, cómo descubrimos el terror, sino acerca de la cuestión de qué es y cómo representamos el terror mismo y cuáles son sus mecanismos discursivos y performativos. Es el problema ontológico que se presenta en Breaking Bad (McHale, 1987:5) ya que en el proceso de transformación de un hombre bueno a un hombre malo, Heisenberg, ni en los últimos momentos de su actuación, deja de ser Walter White, el bueno. Esta identidad desconcertante para sí y los suyos queda perfectamente reflejada en el desconcierto de Skyler, su esposa, en el primer capítulo (Gilligan, 2008), ante la revitalización sexual de su marido. El «ieres tú, Walt?» planeará ya, indefectiblemente, hasta el final de la serie. Es, en analogía con los propósitos borgianos, una superación de los maniqueísmos clásicos del género negro: «De una cierta interpretación post-épica del western, salpicada por notas de sátira social, pasamos a los territorios de la ambigüedad moral y a 
la estética nocturna del film noir en su variante contemporánea de thriller metafísico» (Fernández Pichel, 2013: 118).

\section{Heisenberg: las máscaras del monstruo.}

Cuando al final de la serie, en el último capítulo (Gilligan, 2013), y como colofón a las cinco temporadas de rodaje, Walter White se describe como un monstruo o afirma que todo su periplo por el lado oscuro de la vida lo hizo por sí mismo, «para mantenerse vivo», nos está dando muchas de las claves interpretativas de esta ficción. La sociopatía y ludopatía que esconde este gánster - oculto en un corriente padre de familia - son el motor que proporciona la vitalidad de unos meses de vida y la recompensa a cinco décadas de frustraciones y sumisiones. Walt continúa delinquiendo, a pesar de que ya ha satisfecho su propósito económico, debido a su adicción al poder y a su ego desmedido que lo lleva a querer «fundar un imperio» 5 .

Walter White es un monstruo, en efecto. Al final de la serie computa un importante número de víctimas, a través de asesinatos, estafas, mentiras y deslealtades. La degradación de este pusilánime profesor de química, que va descomponiendo todo lo que toca («una bomba de relojería», profetiza el sicario Mike Ehrmantraut), alcanza lo más sagrado para él y, en principio, el motor último de sus actividades ilícitas: su familia.

Pero si la posmodernidad supone un cuestionamiento de la hegemonía de ciertos valores y ciertas narrativas (Lyotard, 1989: 12), Walter White no puede ser más que un monstruo posmoderno, en la condición biforme que hemos adelantado:

El sujeto posmoderno, sea cual sea su modalidad, imprime a los protagonistas de las novelas un afán de deconstrucción no sólo de su propia identidad y psicología, sino también de su relación —o, más bien, incapacidad de relación- con los otros. Veremos más adelante cómo influye en los contenidos de las novelas: percepción esquizofrénica de la realidad, incomunicación, fragmentación de las emociones, pérdida de sentido del mundo, paranoia espacio-temporal, ausencia de relación entre el cuerpo y la mente (Lozano Mijares, 2007: 167).

Esta deconstrucción de su personalidad se apoya en su representación monstruosa que se contrapone a la nobleza de su batalla: legar un patrimonio solvente a una familia frágil y en precariedad económica, en una sociedad que lo infravalora y lo trata con una insultante condescendencia. La abnegación de su batalla, la valentía al enfrentarse al cáncer, la inicial dignidad de afrontar los costes sanitarios por sí solo, dirige al espectador, desde el inicio, a una empatía con el anti-héroe ${ }^{6}$. Bien es verdad que, en ningún momento, Breaking Bad traspasa la frontera de formas de violencia que serían inaceptables para el espectador, como la violencia de género o familiar, menos tolerables para los mecanismos de atracción de audiencia, a través de la trama doméstica que atrapa a espectadores de

\footnotetext{
${ }^{5}$ Vargas Iglesias (2013: 178) observa en la condición fálica de Walter White su pulsión por delinquir, por recuperar su posición como figura paterna (a veces arrebatada por su cuñado Hank). La montaña de billetes (o la recuperación del establecimiento del lavado de coches) cumplen esta satisfacción.

${ }^{6}$ En este caso, operaría la función catártica del monstruo defendida por Gil (2006: 12): «Os monstros, felizmente, existem não para nos mostrar o que não somos, mas o que poderíamos ser»
} 
varias franjas etarias, base de tanto de las comedias, como de los dramas seriales televisivos (Torre, 2016: 472).

El egoísmo confeso del protagonista («lo hice para sentirme vivo») parece contradecirse con la sentida despedida de la pequeña Holly en el último capítulo y la última, afectuosa y furtiva mirada que dirige a Walter Jr, que apuntala ya la dualidad constructiva del personaje. Aun así, la confesión de Walt también nos reafirma en una intuición que se va consolidando a medida que avanza la trama. Walter quiere sentirse vivo, a partir del momento en que se sabe condenado por el cáncer. El papel de malvado le resulta estimulante y adictivo a medida que se va sintiendo a gusto con el alter ego creado: el disfraz de Heisenberg, que responde al patrón del gánster habitual del género cinematográfico. Así se expresaba Little Melvin Williams ${ }^{7}$, narco de Baltimore, sobre el que se base el personaje de Avon Barksdale en The Wire:

«No es fácil comprarle a tu hija un coche desde la sala de visitas [de la prisión], aunque tengas dinero más que suficiente —dijo-. Así que te preguntas: «¿Cuándo no tuve dinero suficiente? ¿Por qué continué en el negocio cuando hacía tiempo que tenía todo el dinero que quería?»

Porque no es por el dinero.

«Es por tener la sartén por el mango —concedió Williams, reflexionando sobre su legendario estatus en el tráfico de drogas de la Costa Este—. Tener la sartén por el mango es adictivo» (Álvarez, 2013: 107).

Las transformaciones en la personalidad de White se corresponden con esta avaricia fálica y con el análogo proceso de masculinización. ${ }^{8}$ Además de la renovada energía sexual, comienza a reproducir actitudes de dominio machista con Skyler, así como a ocupar la posición paterna y paternal, usurpada en ocasiones por Hank, prototipo de la masculinidad de la que adolece el Walter White de los primeros capítulos 9 :

Así, con el personaje interpretado por Dean Norris el equipo de guionistas hizo u magnífico trabajo a la hora de presentárnoslo: en plena fiesta de cumpleaños de Walter vemos a un personaje bravucón y supuestamente gracioso, alardeando de su nueva arma y de los narcotraficantes que detiene: es Hank, que se ha convertido en el centro de atención de todo el mundo. Mientras, a su lado vemos a Walter, su cuñado, sin carisma ni valentía. Sólo han hecho falta cinco segundos para saber a qué tipo de personaje nos enfrentamos (Buenavista Galván, 2013: 244).

En la autoafirmación de White como Heisenberg, no resulta menos importante la construcción de un retrato y una identidad gansteril, cuyo papel va a ser interpretado con mayor seguridad a lo largo de la serie. Así se percibe en el tránsito que va desde la primera aparición de Heisenberg —más para ahuyentar miedos - , frente al descerebrado narco, Tuco Salamanca (temporada 1, capítulo 6; Mastras y Hughes, 2008), al Heisenberg que, ya en la última temporada, obliga, con seguridad en sí mismo, a uno de sus nuevos socios a decir su nombre «Heisenberg», para dejar bien claro quién manda («Say my name» temporada 5, capítulo 7; Schnauz, 2012). Al fin y al cabo, Heisenberg era el hombre que había descabezado toda la cúpula del mercado de metanfetamina de Nuevo México. El poder

\footnotetext{
${ }^{7}$ El propio Williams, ya rehabilitado, tendrá un papel en la serie como reverendo.

${ }^{8}$ Aspecto desarrollado por Vargas Iglesias (2013).

${ }^{9}$ Por ejemplo, cuando en una fiesta familiar, en que celebran la retracción del cáncer —en una situación que crea un paralelismo contrastivo con la conmemoración del cumpleaños del primer capítulo- Walter emborracha a Walter Jr. desafiando a Hank y reestableciendo la figura paternal en el hogar de los White.
} 
transformador de la química, con que el profesor White instruía a sus alumnos había obrado el milagro en la construcción del nuevo hombre: Heisenberg, el moderno Prometeo.

Por lo tanto, la gran estrategia de Walter para enfrentarse al espectro de posibles enemigos, entre los que se encuentran no sólo los narcotraficantes, sino también los drogadictos y la DEA, es una construcción simbólica, un relato que canta las hazañas de un cocinero del que sólo se sabe que se llama Heisenberg, como cantan Los Cuates de Sinaloa en el cold open de «Negro y Azul» (2x07), y cuyo retrato robot sólo indica que lleva sombrero, bigote y gafas oscuras (Hernández Santaolalla, 2013: 132).

De modo que en la configuración del personaje, del mito, de la máscara jugará un importante papel la imagen y el retrato, con el que Heisenberg pretende soltar amarras con Walter White. Resulta, no obstante, significativo que la primera transformación del aspecto del protagonista, rapándose el pelo y dejándose perilla, suceda nada más conocer el diagnóstico de cáncer. La renovada imagen parece encaminada a componer la efigie con que White pretende ser recordado, espantando, ora los miedos al aspecto desmejorado que pueda ocasionar la enfermedad, ora la apariencia bonachona que comienza a detestar. La renovada apariencia del protagonista pone de relieve la relación entre retrato e inmortalidad, aquella que White busca a través de Heisenberg:

A preocupação de imortalidade não é de orden estritamente metafísica, mas também, como aponta o mesmo ensaísta, de ordem estética: no fundo, trata-se de construir esteticamente uma presença eterna, a da verdade de um rosto absolutamente coincidente com a verdade do retrato. Não uma representação ou uma reprodução duradoura, mas uma re-criação (num sentido muito idêntico ao que encontramos na estatuária funerária egípcia e nos retratos de Faium em particular), interpretados como prolongamentos efectivos do sujeito defunto e suportes imperecíveis do seu elemento vital. É nisto sobretudo que «a estética do retrato implica uma metafísica» (Ribeiro, 2008: 275).

El impacto performativo de la imagen comienza a dar sus frutos enseguida y Walter junior exclamará entre sorprendido y divertido que su padre ahora parece «un malo». Esta caracterización de malvado de película, y que va dando forma al personaje, se va construyendo a medida que avanzan los capítulos: termina incorporando las gafas de sol oscuras y el sombrero negro que compondrán la figura icónica y temerosa de Heisenberg, concretada en los retratos robot o en el dibujo a lápiz que conservan los hermanos Salamanca del hombre que asesinó a su primo, y a quien quieren vengar ${ }^{10}$.

La imagen de Heisenberg, en consecuencia, opaca a White, en la medida que contribuye a la construcción del «macho alfa» que reina en la estructura piramidal del negocio del narcotráfico. En la elaboración de su figura, juegan un papel importante los espejos, como proyección, más que como representación de White, a quien Heisenberg pretende trascender:

A utilização do espelho, a metáfora convencional da pintura percebida como devolução e/ou revelação do eu-próprio, entre o ícone absoluto e o símbolo epifânico, assume nos (auto)retratos contemporâneos pragmáticas dissonantes, e particularmente eloquentes no sentido de um distanciamento da função de restituição da imagem entendida como crédito de visibilidade. Incluído como «pintura» dentro do espaço do quadro (na esteira do experimentum crucis a que alude Eco), o espelho deixa de ser simples prótese perceptiva, prolongando o alcance do órgão visual, para transformar-se na sua própria caricatura. Quer se

\footnotetext{
${ }^{10}$ Hermida (2013) en su análisis sobre la funcionalidad del color en Breaking Bad afirma que los colores beige y blanco predominan en la caracterización del primer Walter White, así como en la representación de Heisenberg se impone el negro, «el color de la negación. Simboliza el poder y la muerte, se asocia con la oscuridad y la maldad, infunde respeto y transmite miedo y desconfianza» (Hermida, 2013: 272)
} 
trate de espelhos deformantes ou e espelhos planos, o espelho pintado é agora sinal de um «exercício contrafactual» com funções directa ou medianamente alucinatórias (Ribeiro, 2008: 304).

La fascinación que siente al ver en el espejo su renovado aspecto o lo bien que le sienta el sombrero negro o la mecanización gestual al desenfundar de la cazadora su primera pistola, le hace sentirse como un John Wayne de western o un duro del género negro que configuran el imaginario cultural sobre el que se construye Breaking Bad y que, de alguna forma, termina parodiando.

Asistimos, pues, a una cierta carnavalización del sujeto, del héroe, del arquetipo y, por supuesto, del género. Con la incorporación de las máscaras, Walter no solo pretende acomodarse en el papel de gánster, sino también afirmar su condición fálica y patriarcal, expresada en renovadas prácticas de sexualidad y paternidad, que reorientan su rol familiar.

Nada nuevo, sin embargo, si se contemplan los tratamientos literarios del relato negro, en concreto en su realización metafísica. Como en «La muerte y la brújula»: «Una discordia de silbidos y de cornetas ahogó la voz del delator. Después, la comunicación se cortó. Sin rechazar la posibilidad de una broma (al fin, estaban en carnaval)» (Borges, 1995: 152).

\section{Persecución y juego en Breaking Bad: Jano Bifronte en Albuquerque}

Heisenberg, como el Lönnrot de «La muerte y la brújula», «se creía un puro razonador, un Auguste Dupin, pero algo de aventurero había en él y hasta de tahúr» (Borges, 1995: 148).

Un tahúr que planea todos los movimientos con la precisión del jugador que es. Breaking Bad, como «La muerte y la brújula», es un juego de némesis y espejos, un juego persecutorio: el que establecen Walter White y Gus Frings, en la cuarta temporada, en un duelo de inteligencias y el que se establece entre Hank Schrader y Heisenberg, que cobra su sentido en la anagnórisis de los últimos capítulos, desmadejado, como se ha dicho, por el libro de Whitman. Podríamos decir que el duelo de Mr. Hyde-Heisenberg contra el agente Schrader, se apoya en la fraterna relación de Jekyll-Walter y Hank, como expresión lograda de los espejos y simetrías borgianas. De hecho, es al final, en el antepenúltimo capítulo, cuando Walter quiere sobreponerse a Heisenberg, intentando evitar la muerte de su cuñado, asumiendo la culpabilidad y renunciando al patrimonio acumulado, que ofrece a la banda de neonazis, como contrapartida para que dejen vivo a Hank. Walter quiere matar a Heisenberg y liberarse de él, quizás consciente por primera vez de lo lejos que ha llegado la partida.

Sin embargo, ha jugado mal sus cartas y se queda sin apenas dinero y no logra evitar la ejecución de Hank, quien, en el momento de su ajusticiamiento se afirma, no como tal, sino como el agente Schrader, cortando el vínculo sentimental con su «brother in law» y asumiendo que ha sido vencido por Heisenberg. La partida había llegado a su fin y el monstruo había devorado a Hank, pero también a White, su creador.

De hecho, no parecen ser los propósitos de White que Heisenberg se hubiese salido con la suya. Como el Red Scharlach de Borges, va diseminando el campo de pistas, seguro de que el pertinaz Schrader terminará encontrándolo. Tal vez consiguiendo la cuadratura del círculo: él comunicando 
urbi et orbi su inteligencia (su competencia para crear un producto único - aunque nocivo- y la construcción de un imperio de tráfico de estupefacientes) y dejando a su familia en la holgura económica que busca. Por eso, en una merienda familiar insinúa que el verdadero Heisenberg es alguien de una inteligencia superior al vulgar delincuente que Hank cree haber capturado o cuando minusvalora la admiración de su cuñado por los conocimientos químicos de Gale. También la perseverancia de Hank, y su obsesión, le hacen proseguir a pesar de una DEA que da por amortizado el caso, con cualquier chivo expiatorio que le sirva para cerrar el expediente. El agente Schrader es consciente de que tiene a Heisenberg bien cerca. El descuido del libro de Whitman — simbólicamente, en la intimidad de una dependencia de la casa familiar-, impensable en alguien tan meticuloso y precavido como White, puede ser también un indicio del juego detectivesco que Walter propone. En este sentido, la respuesta, como la cábala borgiana, está en un libro y en la química como cábala. Aquella que le concede a Walter la brillante capacidad analítica y hermenéutica, como Scharlach, para ejecutar el crimen, contra la lectura obstinada de su némesis:

Tenemos que imaginar, entonces a Scharlach, un dandy sanguinario y siniestro como lector.

¿Qué lee, dónde, por qué, cuándo, en qué situación? Lee para vengarse de Lönnrot, por lo tanto lee para Lönnrot y contra Lönnrot, pero también con él. Lee desde Lönnrot (como Borges nos recomienda leer algunos textos desde Kafka) para seducirlo y capturarlo en sus redes. Infiere, deduce, imagina su lectura y la duplica, la confirma. Se trata de una suerte de bovarismo forzado, porque Scharlach de hecho obliga a Lönnrot a actuar lo que lee. La creencia está en juego. Lönnrot creen en lo que lee (no cree en otra cosa); lee al pie de la letra, podríamos decir. Mientras que Scharlach, en cambio es un lector displicente, que usa lo que lee para sus propios fines, tergiversa y lleva lo que lee a lo real (como crimen).

Por supuesto, Scharlach y Lönnrot (esto es, el criminal y el detective) son dos modos de leer. Dos tipos de lector que están enfrentados (Piglia, 2005: 35).

De hecho, el conocimiento al servicio del crimen asoma en las conversaciones entre Hank y Walter, donde el primero reflexiona sobre Gale y lo productivo que sería aplicar esos conocimientos para hacer el bien. Aseveración que bien se podría aplicar a su cuñado en el malversado uso de la química: «el lector como criminal, que usa los textos en su beneficio y hace de ellos un uso desviado, funciona como hermeneuta salvaje. Lee mal pero sólo en sentido moral; hace una lectura malvada, rencorosa, un uso pérfido de la letra» (Piglia, 2005: 35).

Este monstruo posmoderno que es White / Heisenberg, como sus antecesores románticos, ofrece una acerada crítica a la sociedad contemporánea en que viven y a los códigos burgueses que imperan, apoyados en una visión acrítica del éxito. Con el plazo de la muerte, White es consciente de su insignificancia en el mundo en que el cariñoso White, el padre y marido abnegado, el cuñado amable y el profesor ejemplar, solo tienen cabida dentro de la condescendencia y la caridad, cuando no el escarnio. Así como el Don Juan Tenorio zorrillesco agota el plazo para salvarse por amor, Walter White, en la época del escepticismo moral y religioso, agota el plazo para condenarse por amor.

El talento personal e intelectual de White sólo consigue aflorar de forma monstruosa en una sociedad amoral e hipócrita (las escenas de sus antiguos socios, ahora billonarios, son elocuentes). White representa el moderno Prometeo que es la creación de Víctor Frankenstein, cuya osadía por su conocimiento químico y por revertir las leyes naturales, en este caso sociales, tiene el castigo de ser 
devorado por su criatura. El Jano bifronte que es Walt-Heisenberg, presente también en el libro de Whitman, configura la dualidad monstruosa del Red Scharlach borgiano de «La muerte y la brújula»:

Busco algo más efímero y deleznable, busco a Erik Lönnrot. Hace tres años, en un garito de la Rue de Toulon, usted mismo arrestó, e hizo encarcelar a mi hermano. En un cupé mis hombres me sacaron del tiroteo con una bala policial en el vientre. Nueve días y nueve noches agonicé en esta desolada quinta simétrica: me arrasaba la fiebre, y el odioso Jano bifronte que mira los ocasos y las auroras daba horror a mi ensueño y a mi vigilia. Llegué a abominar de mi cuerpo, llegué a sentir que dos ojos, dos manos, dos pulmones, son tan monstruosos como dos caras (Borges, 1995: 159)

El equilibrio entre las dos esferas del protagonista resulta, sin embargo, imposible. White querría ser Gus Frings, ahora respetable, ahora narco, en un perfecto dominio de la situación. O eso parecía. Pero la capa de respetabilidad de Gus Frings es desenmascarada por la tenacidad de Hank y la ludopatía de White que ponen en evidencia a este pulcro y self made man que es Frings. La muerte del empresario de Pollos Hermanos, impasible e implacable capo, se representa con un guiño inequívocamente fantástico, que permite poner al descubierto, como el retrato de Dorian Gray, la putrefacción social del Albuquerque de Breaking Bad. Nada más detonar la bomba, tras la emboscada tendida por la inteligencia y las habilidades técnicas de White, vemos salir a Gus impoluto y atusándose la corbata, como si nada hubiese ocurrido, proyectando la sensación de inmortalidad. Una vez más el frío Frings se había salido con la suya. Pero el barrido de la cámara nos muestra, antes de desplomarse, la mitad derecha del cerebro hueco y abrasado por la explosión. Como Dorian Gray, la belleza del próspero, altruista y respetable hombre de negocios se descomponía en la decadencia que aflora en ABQ y en la sociedad americana que Gus Frings representaba. La fragmentación dual del retrato de Frings en el momento de su muerte es la representación simbólica de ello.

Como lo es el retrato final de Walter White, muy lejos del Heisenberg que, con tanto detalle se había esmerado en crear. Aparece desharrapado y con un aspecto decadente, como lo está la otrora cálida vivienda familiar, que se muestra con la cara del derrumbe ético de sus meses de exceso, como un Dorian Gray que, en el momento final, aflora la catadura del hombre que no ha sabido ser.

En suma, Walter es el paradigma de la monstruosidad contemporánea en la línea de lo teorizado por Gil (2006: 13):

Os monstros tornaram-se quotidianos não apenas porque a violência e o mal, a anomalia em geral, se banalizaram [...] mas porque, ao contrário, o domínio tradicional da anomalia se contraiu: há cada vez menos monstros entre os homens reais cujas patologias (autênticas ou ideológicas) se encontram classificadas cada vez mais longe do domínio teratológico.

Al fin y al cabo, la anomalía que es Walter representa la fractura del sueño americano, como una subversión del western, que representa el forajido Heisenberg:

La enorme popularidad de la serie de Vince Gilligan y la entronización de Walter White como nuevo mito de la ficción reside en la habilidad con que la peripecia moviliza en el espectador un desencanto que se corresponde, en un nivel inicial, con el ocaso del idealismo estadounidense. Basta recurrir a la comparativa entre dos planos casi idénticos registrados con un intervalo de sesenta años: en el primero tomado de Río Rojo (Red River, Howard Hawks, 1948), el ganadero Tom Dunson (John Wayne) y su hijo adoptivo Matthew Garth (Montgomery Clift) se sitúan en primer término, de espaldas a la cámara y al lado del carromato que los ha traído desde las tierras tejanas hasta las inmensas praderas de Missouri. En segundo término, más allá 
de ellos, un horizonte y un cielo excelsos, expresión máxima del mensaje de esperanza contenido en la épica del western, ese gran marco genérico que, ya lo hemos visto, sirve de partida para la construcción argumental de Breaking Bad. En contraste con este momento, el piloto de la serie de AMC nos dona un plano similar en su concepción visual, aunque divergente al extremo en lo tocante a su sentido profundo: aquí también vemos la espalda del protagonista, un Walter White sin pantalones que porta un arma en mitad del desierto mientras espera la llegada de lo que imagina son patrullas de la policía. Al fondo, en segundo término, unas elevaciones se recortan contra un límpido cielo azul. En este momento, al final de un trayecto imaginario recogido en dos estampas de existencias apegadas a un escenario, la utopía se ha esfumado, y la presencia en la pantalla encarna entonces el reconocimiento de una «civilización hecha añicos» (Fernández Pichel, 2013: 121)

El drama asoma al final de la quinta temporada, en que el derrumbe de este modesto profesor de química y padre ejemplar ha puesto en evidencia todos los fracasos y disimulos de una sociedad menguante. Aquella que es desenmascarada por el género negro en su versión metafísica, tanto literaria, como televisiva.

A modo de conclusión, con las adaptaciones intermediales descritas se ha pretendido evidenciar la contribución de la narración literaria a la conquista de la autonomía de la ficción televisiva en el campo cultural. Las series de este medio optaron por buscar los recursos para una ficción de calidad en diversos géneros narrativos y referencias culturales consolidadas. Se creaba, así, una nueva alfabetización de productores y espectadores televisivos que aceptaban narraciones diferentes a las que se habían popularizado en el medio.

La construcción narrativa de Breaking Bad y la confección de sus personajes es una excelente muestra de ello. La incorporación de repertorios reconocidos en la tradición literaria y cinematográfica pone, consecuentemente, de relieve un elemento central de la cultura posmoderna: su carácter masivo y la democratización estética de los hábitos de consumo contemporáneos.

\section{Bibliografía citada}

Álvarez, R. (2013): The Wire. Toda la verdad. Barcelona, Principal de los libros.

Borges, J. L. (1956): «La muerte y la brújula», en Ficciones. Madrid-Buenos Aires, Alianza-Emecé, 23. ${ }^{\text {a }}$ edición, 1995.

- (1969): «Prólogo», en W. WhitMan, Hojas de hierba. Barcelona, Lumen, pp. 7-11, 1991.

Benjamin, W. (2015): Baudelaire e a modernidade. Trad. João Barrento. Belo Horizonte, Editorial Autêntica.

Buenavista Galván, A. (2013): ““¡Mejor llama a Saul!”. La importancia del secundario», en S. CoBo Durán y V. HeRnández SANTAOLALlA, coords., Breaking Bad. 530 gramos (de papel) para serieadictos no rehabilitados. Madrid, Errata Naturae, pp. 239-256.

Cobo Durán, S. - Hernández SAnTAOlalla, V., coords. (2013): Breaking Bad. 530 gramos (de papel) para serieadictos no rehabilitados. Madrid, Errata Naturae.

ClÜVER, C. (2011): «Intermidialidade», Pós, 1/2, pp. 8-23.

FERNÁNDEZ PiCHEL, S. N. (2013): «Amado Monstruo. Lo heroico y lo monstruoso en Walter White», en S. Cobo Durán y V. Hernández Santaolalla, coords., Breaking Bad. 530 gramos (de papel) para serieadictos no rehabilitados. Madrid, Errata Naturae, pp. 105-122. 


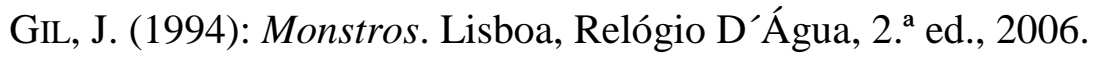

GiLligan, V., prod. (2008): Breaking Bad [Serie de televisión]. USA, Sony Pictures Television.

—, guionista y dir. (2008): «Pilot» [Capítulo de serie de televisión], en V. GiLligAn, prod., Breaking Bad. USA, Sony Pictures Television.

—_, guionista y dir. (2013): «Felina» [Capítulo de serie de televisión], en V. GILLIGAN, prod., Breaking Bad. USA, Sony Pictures Television.

Gilligan, V. - VAN Derwerf, T. (2013): «Así hacemos Breaking Bad», en S. COBO Durán y V. HERNÁNDEZ SANTAOLALLA, coords., Breaking Bad. 530 gramos (de papel) para serieadictos no rehabilitados. Madrid, Errata Naturae, pp. 61-98.

HERMidA, A. (2013): «Breaking Bad: la fórmula del color», en S. CoBo Durán y V. HERNÁNDEZ SANTAOLALLA, coords., Breaking Bad. 530 gramos (de papel) para serieadictos no rehabilitados. Madrid, Errata Naturae, pp. 259-276.

Hernández Santaolalla, V. (2013): «Sucumbiendo a la química del poder. Estrategias de persuasión en Breaking Bad», en S. CoBo Durán y V. HernándeZ SANTAOLALla, coords, Breaking Bad. 530 gramos (de papel) para serieadictos no rehabilitados. Madrid, Errata Naturae, pp. 123-142.

LyOtard, J. F. (1979): A condição Pós-Moderna. Trad. de José Bragança de Miranda. Lisboa, Gradiva, 2. ${ }^{\text {e }}$ ed., 1989.

Lozano Mijares, M. P. (2007): La novela española posmoderna. Madrid, Arco Libros.

MARTin, B. (2014): Hombres fuera de serie. Barcelona, Ariel.

MASTRAS, G., guionista - HugHES, B., dir. (2008): «Crazy Handful of Nothin» [Capítulo de serie de televisión], en V. GILligAn, prod., Breaking Bad. USA, Sony Pictures Television.

McHale, B. (1987): Postmodernist Fiction. New York-Londres, Methuen.

PÉrez BowIE, J. A. - GIL GonzÁlez, A. J., eds. (2017): Ficciones nómadas. Procesos de intermedialidad literaria y audiovisual. Madrid, Pigmalion Edypro.

PRIETO, J. (2017): «El concepto de intermedialidad: una reflexión histórico-crítica», Pasavento. Revista de Estudios Hispánicos, 5 /1, pp. 7-18.

PIGLIA, R. (2005): El último lector. Barcelona, Anagrama.

RAJEWSKY, I. O. (2005): «Intermediality, Intertextuality, and Remediation: A Literary Perspective on Intermediality», Intermedialités, 6 (otoño), pp. 43-64.

RibeIRo, E. (2008). «Poéticas do Retrato - o desgaste das imagens», Diacrítica, 22/3, pp. 265-322.

Romero Bejarano, H. J. (2013): «¿Cómo se cocina Breaking Bad? Análisis de una producción de culto», en S. Cobo DuRÁn y V. HeRnández SANTAOLALla, coords., Breaking Bad. 530 gramos (de papel) para serieadictos no rehabilitados. Madrid, Errata Naturae, pp. 311-328.

SÁnChez MesA, D. - BAETENS, J. (2017): «La literatura en expansión. Intermedialidad y transmedialidad en el cruce entre la literatura comparada, los estudios culturales y los new media studies», Tropelías. Revista de Teoría de la Literatura y Literatura Comparada, 27, pp. 6-27. 
SChNauZ, T., guionista y dir. (2012). «Say my name» [Capítulo de serie de televisión], en V. GILLIGAN, prod., Breaking Bad. USA, Sony Pictures Television.

SchNaUZ, T., guionista - Slovis, M., dir. (2011). «Cornered» [Capítulo de serie de televisión], en V. GILligan, prod., Breaking Bad. USA, Sony Pictures Television.

SePINWALl, A. (2012): The revolution was televised. New York, Simon \& Chuster.

TORRE, T. (2016): Historia de las series. Barcelona, Roca.

VARGAS IGLESIAS, J. L. (2013): «En el nombre del hijo. El mito del padre edípico en Breaking Bad», en S. Cobo Durán y V. HeRnández Santaolalla, coords., Breaking Bad. 530 gramos (de papel) para serieadictos no rehabilitados. Madrid, Errata Naturae, pp. 163-181.

Vila Matas, E. (2013): «La mosca de Breaking Bad», en S. Cobo Durán y V. HeRnándeZ SANTAOLALla, coords., Breaking Bad. 530 gramos (de papel) para serieadictos no rehabilitados. Madrid, Errata Naturae, pp. 99-101. 